\title{
Augmentation of Prolactin Secretion by Estrogen in Hypogonadal Women
}

\author{
S. S. C. Yen, Y. Ehara, and T. M. Siler \\ From the Department of Reproductive Medicine, UCSD School of Medicine, \\ La Jolla, California 92037
}

\begin{abstract}
A B S T RAC T The effect of estrogen on prolactin $(\mathrm{PRL})$ release and gonadotropin suppression was assessed in six experiments performed on four hypogonadal women. Ethinyl estradiol at a dose of $1 \mu \mathrm{g} / \mathrm{kg}$ per day induced a significant elevation of serum PRL levels within the 1st wk of treatment. There was a further rise until a plateau was reached in about 3-4 wk to levels of more than 3 times the initial concentration. This was accompanied by a pattern of increased episodic fluctuation. The corresponding serum luteinizing hormone and follicle-stimulating hormone fell progressively during the study period. These data indicate that a positive feedback relationship between estrogen and PRL release exists in humans.
\end{abstract}

\section{INTRODUCTION}

Evidence that estrogen promotes pituitary prolactin $(\mathrm{PRL})^{1}$ secretion is afforded by the finding of an increased pituitary PRL content and serum PRL concentrations following exogenous estrogen treatment in rats (1-3). This positive feedback relationship was maintained even when a large dose of estradiol benzoate was used $(500 \mu \mathrm{g} /$ day $\times 6$ days $)(2,3)$. In humans, clear evidence for the ability of estrogen to induce PRL release has not been reported. Frantz, Kleinberg, and Noel have found an elevated level of serum PRL in patients with prostatic carcinoma receiving chronic estrogen therapy (4). Administration of diethylstilbestrol

Dr. Ehara was a Research Fellow in Reproductive Endocrinology supported by the Rockefeller Foundation. His present address is Department of Obstetrics and Gynecology, Gunma University School of Medicine, Maebashi-Shi 371, Japan.

Received for publication 20 September 1973 and in revised form 28 November 1973.

${ }^{1}$ Abbreviations used in this paper: EE, ethinyl estradiol; $\mathrm{FSH}$, follicle-stimulating hormone; LH, luteinizing hormone; PRL, prolactin.
(15-50 $\mathrm{mg} /$ day) for $1 \mathrm{wk}$ induced an increase in PRL levels in three of five normal males studied (4).

The availability of a homologous radioimmunoassay for human PRL with necessary specificity and sensitivity for the measurement of circulating $\operatorname{PRL}(5,6)$ has permitted the present investigation, designed to ascertain the relationship between estrogens and PRL release in ovariectomized and post-menopausal human subjects. In addition, the time-course of estrogen treatment on PRL release and gonadotropin inhibition was assessed.

\section{METHODS}

Two postmenopausal women and two ovariectomized subjects volunteered for this study (Table I). They were not taking estrogen or any kind of medication for at least 6 mo before the study. The subjects reported to the ambulatory clinical research facility and were placed at bedrest in a quiet room. A no. 18 Medicut was placed in an antecubital vein and kept open with a slow drip of normal saline. They were awake throughout the test period. Blood samples were obtained at 15-min intervals for a period of $3 \mathrm{~h}$ before and at weekly intervals during ethinyl estradiol (EE) treatment at a pharmacological dose of 1 $\mu \mathrm{g} / \mathrm{kg}$ per day for $4 \mathrm{wk}$. A total of six experiments were performed. Three studies were initiated at $0800 \mathrm{~h}$ (Exps. 1-3), and three studies were begun at $1700 \mathrm{~h}$ (Exps. 4-6). Repeated studies were performed at 6-8 wk apart between EE treatments (Table I).

Serum concentration of PRL, follicle-stimulating hormone $(\mathrm{FSH})$, and luteinizing hormone $(\mathrm{LH})$ were determined by radioimmunoassays (5-8). A sensitive homologous radioimmunoassay system for PRL similar to that described by Sinha, Selby, Lewis, and VanderLaan was employed for this study (5). The detailed characterization of this assay in our laboratory has been reported recently (6). The highly purified human pituitary PRL (Lewis hPRL 201174) was labelled with ${ }^{225} \mathrm{I}$. Rabbit anti-hPRL antiserum and highly purified human pituitary PRL (Lewis 203-1) were used as first antibody and standard, respectively. The coefficient of variation was $14.4 \%$ for interassay error and 8.6 for the intraassay error. Using 50 or $100 \mu 1$ of serum the minimal detectable level in this assay was $4.0 \mathrm{ng} / \mathrm{ml}$. All samples from a serial study were measured in a single 
TABLE I

Effect of EE Treatment on Serum PRL Concentration Determined at IVeekly Intervals for 4 wk

\begin{tabular}{|c|c|c|c|c|c|}
\hline \multirow{3}{*}{$\begin{array}{l}\text { Subject (age) } \\
\text { status }\end{array}$} & \multicolumn{5}{|c|}{ Serum PRL concn $\mathrm{ng} / \mathrm{ml}$ (transverse mean $\pm \mathrm{SE}$ )* } \\
\hline & \multirow[b]{2}{*}{ Control } & \multicolumn{4}{|c|}{ EE treatment $(1 \mu \mathrm{g} / \mathrm{kg}$ per day $)$} \\
\hline & & $1 \mathrm{wk}$ & $2 \mathrm{wk}$ & $3 \mathrm{wk}$ & 4 wk \\
\hline $\begin{array}{l}\text { E. C. (54) } \\
\text { postmenopausal }\end{array}$ & $9.6 \pm 0.4$ & $18.8 \pm 1.0$ & $26.6 \pm 1.1$ & $59.0 \pm 8.6$ & $55.3 \pm 6.6$ \\
\hline $\begin{array}{l}\text { M. D.1 }(56) \\
\text { ovariectomized }\end{array}$ & $5.9 \pm 0.3$ & $21.4 \pm 2.0$ & $39.6 \pm 5.0$ & $56.0 \pm 6.0$ & $33.7 \pm 2.5$ \\
\hline $\begin{array}{l}\text { M. D.2 }(56) \\
\text { ovariectomized }\end{array}$ & $14.3 \pm 1.1$ & $55.2 \pm 4.9$ & $73.9 \pm 9.9$ & $38.7 \pm 2.2$ & $44.3 \pm 4.3$ \\
\hline $\begin{array}{l}\text { M. K. (53) } \\
\text { postmenopausal }\end{array}$ & $9.8 \pm 1.1$ & $34.0 \pm 1.8$ & $58.5 \pm 3.6$ & $39.7 \pm 3.7$ & $30.2 \pm 1.7$ \\
\hline $\begin{array}{l}\text { E. T.1 }(37) \\
\text { ovariectomized }\end{array}$ & $15.3 \pm 0.7$ & $30.0 \pm 1.0$ & $26.5 \pm 0.8$ & $26.5 \pm 1.9$ & $22.2 \pm 1.5$ \\
\hline $\begin{array}{l}\text { E. T.2 (37) } \\
\text { ovariectomized }\end{array}$ & $13.9 \pm 0.5$ & $28.0 \pm 1.9$ & $30.3 \pm 1.1$ & $36.4 \pm 1.2$ & $26.0 \pm 1.9$ \\
\hline Mean $\pm \mathrm{SE}$ & $11.5 \pm 1.5$ & $31.2 \pm 5.3 \ddagger$ & $42.6 \pm 8.0 \ddagger$ & $41.7 \pm 5.4 \ddagger$ & $35.3 \pm 5.1 \ddagger$ \\
\hline
\end{tabular}

* Average of values in samples obtained at 15-min intervals for $3 \mathrm{~h}$.

‡ Significantly higher $(P<0.01)$ when compared with the control value.

assay. The one-tailed Student paired $t$ test was used for statistical analyses.

\section{RESULTS}

Fig. 1 illustrates serum PRL concentrations before and at weekly intervals after initiation of $\mathrm{EE}$ treatment. Because of the episodic nature of $\operatorname{PRL}$ release $(6,9)$, the transverse mean $( \pm \mathrm{SE})$ of PRL concentrations obtained at 15 -min intervals during 3 -h periods was used for quantitative comparison (Table I). Bəfore treatment, serum PRL levels in this group of hypogonadal subjects were comparable to the values found in premenopausal women (6). Without exception, EE at a dose level of $1 \mu \mathrm{g} / \mathrm{kg}$ per day induced a significant elevation of serum PRL levels in all six experiments. This was accompanied by a pattern of an increased episodic fluctuation (Fig. 1).

The enhanced PRL secretion during EE treatment appears to be prompt (within the $1 \mathrm{st} w \mathrm{w}$ ). There was a continuous rise until a plateau was reached in about $3-4$ wk to levels of more than $300 \%$ the initial concentration (Table I and Fig. 2). The corresponding course for serum LH and FSH (transverse mean \pm SE) determined in the same aliquots of sera revealed an opposite pattern. The elevated $\mathrm{LH}(55.0 \pm 14.4 \mathrm{mIU} / \mathrm{ml})$ and FSH $(89.0 \pm 9.2 \mathrm{mIU} / \mathrm{ml})$ levels found during the control studies confirm the hypogonadal state in these subjects (9). With the dose of EE used, the expected negative feedback effect on gonadotropin secretion required 4 weeks to decline from the postmenopausal lev- els to the range found in premenopausal women $(\mathrm{LH}=$ $11.7=1.9 \mathrm{mIU} / \mathrm{ml}, \mathrm{FSH}=18.6 \pm 4.4 \mathrm{mIU} / \mathrm{ml}$ ). In terms of relative change, a greater decline of FSH than $\mathrm{LH}$, especially during the 1 st wk of EE treatment, was observed (Fig. 2).

\section{DISCUSSION}

The data presented here demonstrate that chronic administration of relatively small amounts of $\mathrm{EE}$ to postmenopausal and ovariectomized women induced an augmented pituitary PRL secretion that was accompanied by a pattern of increased fluctuation (Table I and Fig. 1). This action of estrogen is prompt, with serum PRL concentrations more than doubling in $1 \mathrm{wk}$ and reaching a peak by the 3rd wk to levels of more than 3 times the initial concentrations (Fig. 2). It is evident that EE exerted an opposite action between the augmented PRL secretion and the suppressed gonadotropin release. These data represent the first clear demonstration of the enhancement of estrogen on pituitary PRL-release in humans.

In normal male subjects, Frantz, Kleinberg, and Noel have recently shown that large-dose estrogen(diethylstilbestrol, $15-50 \mathrm{mg} /$ day) treatment for $1 \mathrm{wk}$ induced a clear rise in PRL levels in three of five subjects. In patients with prostatic carcinoma receiving chronic estrogen therapy, the mean PRL level was found to be twice the normal male values (20.7 vs. $9.2 \mathrm{ng} / \mathrm{ml}$ ) (4). It should be noted that these studies were based on single 

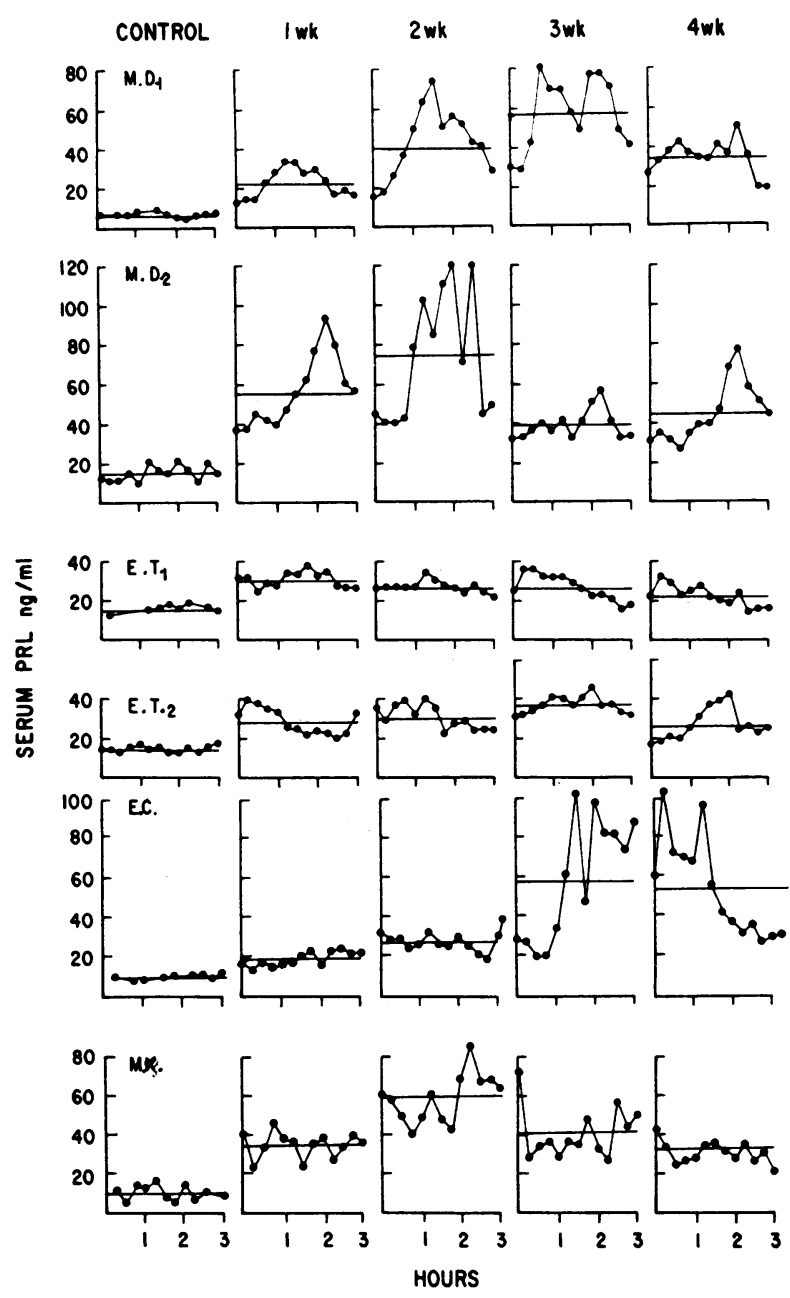

FIGURE 1 Serum PRL concentrations determined at 15min interval before and during treatment with $\mathrm{EE}(1 \mu \mathrm{g} /$ $\mathrm{kg}$ per day) in six experiments performed in four hypogonadal female subjects. The horizontal line represents the transverse mean.

PRL determinations. In view of the recent demonstration of the episodic nature of PRL release $(6,10)$, meaningful assessment of the physiologic and pharmacologic events cannot be established unless frequent sampling at shorter intervals over a period of at least several hours is obtained. This point is clearly illustrated in our study.

From the experimental data obtained in rats, estrogen appears to cause the enhanced PRL release by exerting a dual action via hypothalamic suppression of the PRLinhibiting factor and direct stimulation of pituitary lactotrophs. (1-3). In humans, substantial evidence is now available to indicate a temporal relationship between pituitary PRL secretion and estrogen levels; a rise in PRL concentration parallel with the increase in circu-

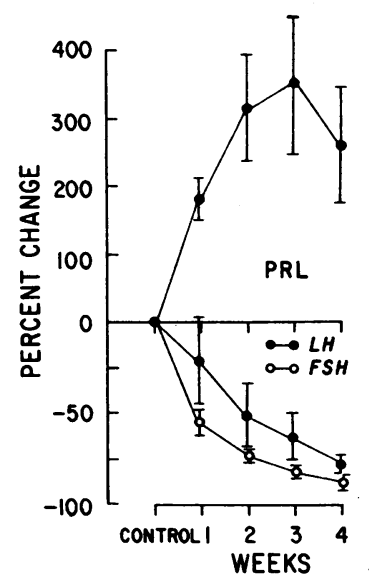

FIgUre 2 The opposite effect of EE between the augmented PRL secretion and suppressed gonadotropin release; data obtained in six experiments performed in four hypogonadal women and expressed as percent change from control. (Vertical bars represent 1 SEM. A significant change [P<0.01 or less] from control was found at all points for $\mathrm{PRL}$ and FSH and at 2nd, 3rd, and 4th wk of EE treatment for LH.)

lating estrogen was found in girls (but not in boys) during late puberty (11) and during pregnancy (12). Although a marked degree of overlap was found, serum PRL levels were significantly greater in females than in males when a large group of samples was examined (6). The lack of an apparent elevation of PRL levels during the preovulatory phase of the cycle $(6,12)$ need not be inconsistent with the present finding of an augmentation of PRL release by estrogen since these studies were based on daily samples and since subtle changes may have escaped a measurable effect. Moreover, a quantitatively greater nocturnal episodic PRL release has been seen during midcycle than during other phases of the cycle (6). Additionally, PRL release has been found to be greater in female than in male subjects under pharmacological stimuli, with agents considered to have their primary action on the hypothalamus such as arginine (13) and perphenazine (14) and in response to direct pituitary stimulation such as administration of thyrotropin-releasing factor $(13,15)$. These collective observations together with our present finding suggest that estrogen exerts a positive feedback effect on pituitary PRL secretion but does not provide evidence favoring primary hypothalamic vs. pituitary or a combined site of action. Participation of other hormonal events in the augmentation of PRL release, especially during pregnancy, should also be considered.

\section{ACKNOWLEDGMENTS}

Reagents for radioimmunoassay of serum $\mathrm{LH}, \mathrm{FSH}$, and PRL were kindly provided by NIAMDD. Before the dis- 
tribution by NIAMDD, materials for PRL radioimmunoassay were gifts from Dr. U. J. Lewis and W. P. Vanderlaan of Scripps Clinic and Research Foundation. The excellent technical assistance was provided by $\mathbf{P}$. Webster and $\mathrm{T}$. Vargo.

This research was supported by The Rockefeller Foundation (70029).

\section{REFERENCES}

1. Meites, J., K. H. Lu, W. Wuttke, C. W. Welsch, H. Nagasawa, and S. K. Quadri. 1972. Recent studies on functions and control of prolactin secretions in rats. Recent Prog. Horm. Res. 28: 471.

2. Ajika, K., L. Krulich, C. P. Fawcett, and S. M. McCann. 1972. Effects of estrogen on plasma and pituitary gonadotropins and prolactin, and on hypothalamic releasing and inhibiting factors. Neuroendocrinology. 9: 304.

3. Nicoll, C. S., and J. Meites. 1964. Prolactin secretion in vitro: Effects of gonadal and adrenal corticosteroids. Proc. Soc. Exp. Biol. Med. 117: 579.

4. Frantz, A. G., D. L. Kleinberg, and G. L. Noel. 1972. Studies on prolactin in man. Recent Prog. Horm. Res. 28: 527 .

5. Sinha, Y. N., F. W. Selby, U. J. Lewis, and W. P. VanderLaan. 1973. A homologous radioimmunoassay for prolactin. J. Clin. Endocrinol. Metab. 26: 509.

6. Ehara, Y., T. M. Siler, G. VandenBerg, Y. N. Sinha, and S. S. C. Yen. 1973. Circulating prolactin levels during the menstrual cycle: Episodic release and diurnal variation. Am. J. Obstet. Gynecol. 117: 962.

7 Yen, S. S. C., O. Llerena, B. Little, and O. H. Pearson.
1968. Disappearance rates of endogenous luteinizing hormone and chorionic gonadotropin in man. J. Clin. Endocrinol. Metab. 28: 1763.

8. Yen, S. S. C., L. A. Llerena, O. H. Pearson, and A. S. Littell. 1970. Disappearance rates of endogenous folliclestimulating hormone in serum following surgical hypophysectomy in man. J. Clin. Endocrinol. Metab. 30: 325.

9. Yen, S. S. C., C. C. Tsai, G. VandenBerg, and R. Rebar. 1972. Gonadotropin dynamics in patients with gonadal dysgenesis; a model for the study of gonadotropin regulation. J. Clin. Endocrinol. Metab. 35: 897.

10. Sassin, J. F., A. G. Frantz, E. D. Weitzman, and S. Kaplen. 1972. Human prolactin: 24-hour pattern with increased release during sleep. Science (Wash. D. C.). $177: 1205$.

11. Ehara, Y. S., S. S. C. Yen, and T. M. Siler. 1973. Serum prolactin levels during puberty. J. Clin. Endocrinol. Metab. In press.

12. Hwang, P., H. Guyda, and H. Freisen. 1971. A radioimmunoassay for human prolactin. Proc. Natl. Acad. Sci. U. S. A. 68: 1902.

13. Rakoff, J. S., T. M. Siler, Y. N. Sinha, and S. S. C. Yen. 1973. Prolactin and growth hormone release in response to sequential stimulation by arginine and synthetic TRF. J. Clin. Endocrinol. Metab. 37: 641.

14. Buchman, M. T., and G. T. Peake. 1973. Estrogen potentiation of phenothiazine-induced prolactin secretion in man. Clin. Res. $21: 487$.

15. Jacobs, L. S., P. J. Snyder, R. D. Utiger, and W. H. Daughaday. 1973. Prolactin response to thyrotropinreleasing hormone in normal subjects. J. Clin. Endocrinol. Metab. 36: 1069. 